\title{
LA OBJECIÓN DE CONCIENCIA MÉDICA E INSTITUCIONAL EN CASOS DE ABORTOS NO PUNIBLES. DERIVACIONES DEL FALLO “F.,A.L.” DE LA CORTE SUPREMA DE JUSTICIA DE LA NACIÓN ${ }^{1}$
}

\author{
MEDICAL AND INSTITUTIONAL CONSCIENTIOUS OBJECTION IN CASES OF \\ NON-PUNISHABLE ABORTIONS. DERIVATIONS OF THE RULING "F., A.L." OF \\ THE SUPREME COURT OF JUSTICE OF THE NATION
}

Por Carlos Francisco Ferrer ${ }^{(*)}$

Resumen: El presente trabajo analiza el estado actual de la cuestión de la objeción de conciencia médica, personal e institucional, a partir de lo resuelto en el precedente $F$., A.L s/medida autosatisfactiva de la Corte Suprema de Justicia de la Nación, de fecha 13 de marzo de 2012, y las interpretaciones disímiles que sobre el tema se han hecho en los protocolos y guías establecidos a partir del mismo, particularmente en el orden nacional y el de la Provincia de Córdoba. Es que si bien el máximo tribunal nacional trató con especificidad uno de los supuestos de aborto no punible (para interrumpir un embarazo producto de un abuso sexual), la reglamentación sanitaria, avanzó sobre el otro supuesto (aborto terapéutico) realizando una intelección que, por su amplitud, se traduce en los hechos, bajo la invocación de un derecho, en la posibilidad de interrupción impune de todo embarazo no deseado. Es por eso que se pretende especialmente esclarecer cuales son los alcances que, desde ambos aspectos deben darle el profesional o la institución a la cuestión emergente (que se exterioriza en la tensión entre la obligación y el derecho), en el entendimiento que involucra derechos fundamentales de los que toda persona goza, tanto sea cuando ejerce de manera individual el arte de curar, como cuando se asocia y crea ámbitos con iguales propósitos, inspirados -en ambos casos- en determinados principios y valores. En suma, se trata de evaluar, hasta qué punto se puede imponer el deber de hacer, promover o facilitar la realización de prácticas que se oponen a las convicciones más profundas del ser humano, y que reconocen contrarias a la razón y motivos de su vocación médica.

Palabras clave: Salud, embarazo no deseado, convicciones éticas, persona, muerte.

Abstract: This paper analyzes the current state of the issue of medical, personal and institutional conscientious objection, based on what was resolved in the preceding F., AL s / self-satisfactory measure of the Supreme Court of Justice of the Nation, dated 13 March 2012, and the dissimilar interpretations that have been made on the subject in the protocols and guidelines established from it, particularly in the national order and that of

${ }^{1}$ Artículo recibido el 9 de septiembre de 2020 y aprobado para su publicación el 24 de septiembre de 2020.

(*) Abogado. Profesor de Derecho Procesal Penal (UCC y UNC), y de Técnicas de Litigación Oral (UCC). Director de la Sala de Derecho Procesal Penal (UCC). Ex Decano de la Facultad de Derecho y Ciencias Sociales de la UCC. Ex Fiscal de Cámara en lo Criminal de la Provincia de Córdoba. Contacto: carlos ferrergm@hotmail.com 
the Province of Córdoba. Although the highest national court specifically dealt with one of the cases of non-punishable abortion (to interrupt a pregnancy as a result of sexual abuse), the health regulations advanced on the other case (therapeutic abortion) carrying out an intellection that, for Its breadth translates into the facts, under the invocation of a right, in the possibility of interruption with impunity of any unwanted pregnancy. That is why it is especially intended to clarify what are the scope that, from both aspects, the professional or the institution must give to the emerging question (which is expressed in the tension between the obligation and the right), in the understanding that it involves fundamental rights one that everyone enjoys, both when they individually exercise the art of healing, and when they associate and create areas with the same purposes, inspired -in both casesby certain principles and values. In short, it is about evaluating to what extent the duty to do, promote or facilitate the realization of practices that are opposed to the deepest convictions of the human being, and that they recognize contrary to the reason and motives of their vocation can be imposed. medical.

Keywords: Health, unwanted pregnancy, ethical convictions, person, death.

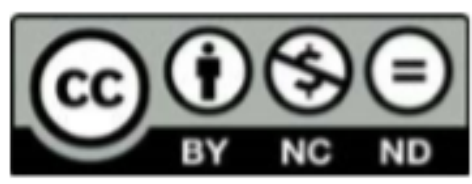

Artículo publicado bajo Licencia Creative Commons Atribución-No Comercial-Sin Derivar. (C) Universidad Católica de Córdoba

DOI http://dx.doi.org/10.22529/rfd.2020(3)03 
LA OBJECIÓN DE CONCIENCIA MÉDICA E INSTITUCIONAL

EN CASOS DE ABORTOS NO PUNIBLES. DERIVACIONES

DEL FALLO “F.,A.L." DE LA CORTE SUPREMA DE JUSTICIA

DE LA NACIÓN

"No se trata solamente de cambiar la historia cada vez que se necesite para tutelar la imagen del poder (...), sino de convencer a todos los hombres de que sus ideas, sus convicciones, sus valores, sus principios morales, hasta sus amores (...) no tienen ningún sentido y ninguna importancia, porque la verdad misma está en las manos del poder - es decir, no existe... „2

\section{Introducción.}

Con fecha 13 de marzo de 2012, en los autos "F., A. L. s/ medida autosatisfactiva" (en adelante, “F., A.L.”), en un caso originado en el pedido de autorización judicial para la realización de un aborto no punible de una niña adolescente violada por su padrastro (solicitud que finalmente había sido acogida favorablemente por el máximo tribunal de la provincia de Chubut, y la práctica abortiva ya realizada en un ámbito hospitalario), no obstante haberse tornado abstracta la situación, la Corte Suprema de Justicia de la Nación (en adelante C.S.J.N.), dio trámite al recurso deducido "con la finalidad de que el criterio del Tribunal sea expresado y conocido para la solución de casos análogos que puedan presentarse en el futuro”. De tal manera, tras declarar procedente la impugnación, confirmó la sentencia apelada3 .

El fallo dejó sentado que lo dispuesto por el art. 86 inc. $2^{\circ}$ del C. Penal respecto de los supuestos de no punibilidad de un aborto consentido por la mujer como el referido, debe interpretarse en el sentido que "no resulta punible la interrupción del embarazo proveniente de toda clase de violación, porque una exégesis en sentido contrario -que reduzca la no punibilidad de esta práctica al caso de una incapaz mental amplía sustancialmente el alcance del castigo penal y niega, a

\footnotetext{
2 SARTEA, Claudio, en "¿Qué objeción? ¿qué conciencia? reflexiones acerca de la objeción de conciencia y su fundamentación conceptual", donde hace un comentario de "Rebelión en la granja" de George Orwell; en http://aebioetica.org/revistas/2013/24/82/391.pdf

3 C.S.J.N. en "F., A.L.", considerando $\mathrm{n}^{\circ}$ 5, del voto de los ministros Lorenzetti, Highton de Nolasco, Fayt, Maqueda y Zaffaroni, parágrafo 17; los ministros Petrachi y Argibay, votaron individualmente, de manera coincidente Ver el fallo completo en http://www.saij.gob.ar/corte-suprema-justicianacion-federal-ciudad-autonoma-buenos-aires--medida-autosatisfactiva-fa12000021-2012-0313/123456789-120-0002-10ts-eupmocsollaf.
} 
LA OBJECIÓN DE CONCIENCIA MÉDICA E INSTITUCIONAL

EN CASOS DE ABORTOS NO PUNIBLES. DERIVACIONES

DEL FALLO “F.,A.L." DE LA CORTE SUPREMA DE JUSTICIA

DE LA NACIÓN

toda otra víctima de una violación que se encuentre en esa situación, el derecho a acceder a esta práctica" 4 (el destacado me pertenece).

Teniendo en cuenta el apremio que representan los tiempos de un embarazo en curso, añadió también que la judicialización del caso, como condición previa para la práctica del aborto no punible, sometiéndolo a los avatares propios de una investigación penal del abuso contra la mujer embarazada, "además de ser innecesaria e ilegal, es cuestionable porque obliga a la víctima del delito a exponer públicamente su vida privada, y es también contraproducente porque la demora que apareja en su realización pone en riesgo tanto el derecho a la salud de la solicitante como su derecho al acceso a la interrupción del embarazo en condiciones seguras" 5 .

De allí que "quien se encuentre en las condiciones allí descriptas, no puede ni debe ser obligada a solicitar una autorización judicial para interrumpir su embarazo, toda vez que la ley no lo manda, como tampoco puede ni debe ser privada del derecho que le asiste a la interrupción del mismo ya que ello, lejos de estar prohibido, está permitido y no resulta punible"6; y, "si concurren las circunstancias que permiten la interrupción del embarazo, es la embarazada que solicita la práctica, junto con el profesional de la salud, quien debe decidir llevarla a cabo y no un magistrado a pedido del médico"”.

La acreditación de dichas circunstancias "supone tan sólo como necesario que la víctima de este hecho ilícito, o su representante, manifiesten ante el profesional tratante, declaración jurada mediante, que aquel ilícito es la causa del embarazo, toda vez que cualquier imposición de otro tipo de trámite... significará incorporar requisitos adicionales a los estrictamente previstos por el legislador penal"8.

4. C.S.J.N. en "F., A.L.", considerando ${ }^{\circ} 17$.

5 C.S.J.N. en "F., A.L.", considerando $\mathrm{n}^{\circ} 19$.

${ }^{6}$ C.S.J.N. en "F., A.L.", considerando $\mathrm{n}^{\circ} 21$.

7 C.S.J.N. en "F., A.L.", considerando $\mathrm{n}^{\circ} 22$.

${ }^{8}$ C.S.J.N. en "F., A.L.", considerando $\mathrm{n}^{\circ} 27$. 
Con base en dicho razonamiento, enfatizó además el pronunciamiento, que "es el Estado, como garante de la administración de la salud pública, el que tiene la obligación, siempre que concurran las circunstancias que habilitan un aborto no punible, de poner a disposición, de quien solicita la práctica, las condiciones médicas e higiénicas necesarias para llevarlo a cabo de manera rápida, accesible y segura" 9 .

Finalmente, en lo que aquí interesa, los magistrados culminan exhortando "a las autoridades nacionales $y$ provinciales a implementar $y$ hacer operativos, mediante normas del más alto nivel, protocolos hospitalarios para la concreta atención de los abortos no punibles a los efectos de remover todas las barreras administrativas o fácticas al acceso a los servicios médicos", debiéndose prever "un adecuado sistema que permita al personal sanitario ejercer su derecho de objeción de conciencia sin que ello se traduzca en derivaciones o demoras que comprometan la atención de la requirente del servicio”, para lo cual, "deberá disponerse que la objeción sea manifestada en el momento de la implementación del protocolo o al inicio de las actividades en el establecimiento de salud correspondiente, de forma tal que toda institución que atienda a las situaciones aquí examinadas cuente con recursos humanos suficientes para garantizar, en forma permanente, el ejercicio de los derechos que la ley le confiere a las víctimas de violencia sexual"10 (los destacados me pertenecen)

\section{Obiter dictum con exhortaciones}

Los magistrados integrantes de la máxima jerarquía del Poder Judicial de nuestro País, han realizado una interpretación de normas jurídicas -con implicancias constitucionales- que normalmente es propia de su incumbencia.

\footnotetext{
9 C.S.J.N. en "F., A.L.", considerando $\mathrm{n}^{\circ} 25$.

${ }^{10}$ C.S.J.N. en "F., A.L.", considerando ${ }^{\circ} 29$.
}

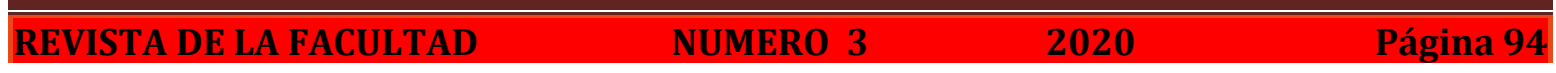


LA OBJECIÓN DE CONCIENCIA MÉDICA E INSTITUCIONAL

EN CASOS DE ABORTOS NO PUNIBLES. DERIVACIONES

DEL FALLO "F.,A.L." DE LA CORTE SUPREMA DE JUSTICIA

DE LA NACIÓN

Ahora bien, en tanto su pronunciamiento recayó atípicamente en un caso devenido en abstracto que en otras ocasiones (tal como lo solicitó el Procurador Fiscal en el presente) hubiera merecido un rechazo in limine por la consumación del aborto ya concretado al tiempo de la decisión, y por incluir exhortaciones explícitas dirigidas a los tribunales inferiores, como también a "autoridades nacionales, provinciales y de la Ciudad Autónoma de Buenos Aires, con competencia en la materia, a implementar y hacer operativos, mediante normas del más alto nivel, en los términos aquí sentados, protocolos hospitalarios para la concreta atención de los abortos no punibles y para la asistencia integral de toda víctima de violencia sexual"11, tal parece que en este caso, casi legisferando, los jueces vienen a suplir, a través de un pronunciamiento judicial, el vacío normativo existente.

Y si bien el Máximo Tribunal trató, tan sólo el supuesto no punible de interrupción de un embarazo consecuencia de una violación (art. 86 inc. $2^{\circ}$ del Código Penal), se le ha dado a lo decidido proyecciones que abarcan los otros supuestos eximidos de penalidad contemplados en el primer inciso del mismo artículo. Son los que se dan en llamar genéricamente abortos terapéuticos. Es decir, cuando se los autoriza (excluyéndolos de la amenaza punitiva) si el avance del embarazo representa un riesgo grave para la vida o la salud de la gestante.

\section{Los protocolos médicos derivados del caso "F., A.L."}

Casi coincidentemente a la resolución judicial comentada, se sucedieron decididamente distintas acciones en línea con ella, en las jurisdicciones nacional y provinciales, tendientes a dar cumplimiento a la exhortación de los jueces supremos.

A la vez, con pretendido sustento en razones de distinta índole, pero que hicieron eje en el derecho de las mujeres a "decidir sobre su cuerpo", con la aspiración de vincular la interrupción del embarazo no deseado (o mejor dicho, al aborto

${ }^{11}$ C.S.J.N. en "F., A.L.", punto $2^{\circ}$ de la parte resolutiva. 
LA OBJECIÓN DE CONCIENCIA MÉDICA E INSTITUCIONAL

EN CASOS DE ABORTOS NO PUNIBLES. DERIVACIONES

DEL FALLO "F.,A.L." DE LA CORTE SUPREMA DE JUSTICIA

DE LA NACIÓN

deseado) como una cuestión inherente -desde una concepción amplia aunque sesgada- a la protección de su salud, la discusión sobre el tema se instaló en el Congreso de la Nación (2018), con el deliberado propósito de reformar el Código Penal, prohijando la eliminación de la figura del aborto decidido o consentido por la mujer embarazada (o de sus representantes legales, en caso de ser menor o incapaz), y el derecho a que dicha práctica sea realizada en forma "legal, gratuita y segura" en las instituciones de salud de nuestro País. La iniciativa fue debatida, sin éxito, sin perjuicio de lo cual, quienes la alentaron, mantienen las expectativas de un nuevo embate, habiéndose anunciado recientemente, desde el Poder Ejecutivo de la Nación, la inminente presentación de un nuevo proyecto de ley cuyo texto se mantiene hasta hoy en reserva.

No obstante, aunque limitada a supuestos de embarazos encuadrables en la causa de justificación y la excusa absolutoria contempladas en el art. 86 del Código Penal (abortos no punibles), la exhortación de la Corte convalidó -se pretende, de manera amplia- la posibilidad de interrumpirlos sin necesidad de judicializar previamente los hechos que los habrían provocado, ni de contar con una autorización judicial, administrativa u otro condicionamiento expreso, y reafirmó la responsabilidad del Estado de garantizar los recursos hospitalarios y profesionales para que tales prácticas sean realizables sin riesgos y sin costo para la gestante que lo peticiona.

Es por ello que, sucesiva y progresivamente, desde diversas órbitas gubernamentales, se fueron adecuando, aprobando y poniendo en práctica, bajo la modalidad de leyes locales, decretos o resoluciones emanadas de las autoridades sanitarias, distintas guías y protocolos hospitalarios.

La primera referencia sobre el punto es la "Guía Técnica para la Atención Integral de Abortos No Punibles", instrumento que fue redactada durante el año 2007, y que tuvo como precedente el documento elaborado por el Programa Nacional de Salud Sexual y Procreación Responsable (PNSSyPR, creado por Ley 
LA OBJECIÓN DE CONCIENCIA MÉDICA E INSTITUCIONAL

EN CASOS DE ABORTOS NO PUNIBLES. DERIVACIONES

DEL FALLO "F.,A.L.” DE LA CORTE SUPREMA DE JUSTICIA

DE LA NACIÓN

$25.673^{12}$, reglamentada por Decreto $\mathrm{n}^{0} 1282 / \mathrm{o3}^{13}$ ) basado en cuatro fuentes principales: "Aborto sin riesgos: Guía técnica y de políticas para sistemas de salud", Organización Mundial de la Salud (Ginebra, 2003); "Norma Técnica para la Atención de la Interrupción Voluntaria del Embarazo (IVE)", Ministerio de la Protección Social (Bogotá, 2006); "Norma Técnica: Atenção Humanizada ao Abortamento”, Ministerio da Saúde (Brasilia, 2005); y “Aborto Legal: Regulaciones Sanitarias Comparadas”, de Ana Cristina González Vélez, Giselle Carino y Juanita Durán, IPPF/WHR (Montevideo, 2007) ${ }^{14}$.

Dicha guía fue actualizada en junio de 2010. En 2015, ya con base en la jurisprudencia que encabeza el presente, fue aprobada como el "Protocolo para la atención integral de las personas con derecho a la interrupción legal del embarazo" 15 , el que finalmente, a poco de asumidas las autoridades de la actual gestión gubernamental del País (el 10 de diciembre de 2019), fue nuevamente actualizado ${ }^{16}$.

En éste instrumento se prevé, para los casos previstos en sendos incisos del art. 86 del Código Penal, la interrupción del embarazo no punible, ejecutados mediante procedimientos medicamentoso (misoprostol), o instrumental (evacuación manual endouterina o con aspiración de vacío), bajo los criterios y condiciones que, en general, fueron considerados en el fallo "F., A.L.".

Con posterioridad, las provincias de Jujuy, La Rioja, Misiones, Salta, San Luis, Santa Cruz, Santa Fe, Tierra del Fuego, Entre Ríos y Chaco, adhirieron al mismo Protocolo Nacional, en tanto que Formosa y San Juan no lo hicieron oficialmente,

${ }^{12}$, Ley 25.673, sancionada el 30/10/2002; promulgada el 21/11/2002; publicada en Boletín Oficial 22/11/2002; en http://www.msal.gob.ar/images/stories/ryc/graficos/o000000677cnt-Leyes-quereconocen-tus-derechos.pdf;

${ }_{13}$ Fecha de Emisión: 23/05/2003; Publicado en: Boletín Oficial 26/05/2003. Ver texto completo en https://www.argentina.gob.ar/normativa/nacional/decreto-1282-2003-85450/texto;

${ }_{14}$ Ver texto completo en http://www.msal.gob.ar/images/stories/bes/graficos/0000000667cntGuia-tecnica-web.pdf

15 Ver texto completo en https://www.argentina.gob.ar/sites/default/files/protocolo ile.pdf

16 Ver texto completo en http://www.msal.gob.ar/images/stories/bes/graficos/o000001792cntprotocolo-ILE-2019-2edicion.pdf 
LA OBJECIÓN DE CONCIENCIA MÉDICA E INSTITUCIONAL

EN CASOS DE ABORTOS NO PUNIBLES. DERIVACIONES

DEL FALLO "F.,A.L." DE LA CORTE SUPREMA DE JUSTICIA

DE LA NACIÓN

pero lo adoptaron. Corrientes, Santiago del Estero y Tucumán, por su parte, figuran sin protocolo propio y tampoco adhirieron al nacional.

En Mendoza, contaban con uno desde el año 2018, optando por seguir utilizándolo dada su similitud con el vigente en la Nación. Algo similar ocurrió con Catamarca, Chubut, Río Negro, Neuquén, Provincia de Buenos Aires, Ciudad Autónoma de Buenos Aires y La Pampa. ${ }^{17}$

El 30 de marzo de 2012, mediante Resolución n ${ }^{\circ}$ 093/12, el Ministerio de Salud de la Provincia de Córdoba, había habilitado su propia Guía de Procedimiento para la Atención de Pacientes que soliciten Prácticas de Aborto no Punibles ${ }^{18}$, pero recién entró en vigencia el 25 de setiembre de 2019, cuando el Tribunal Superior de Justicia de la Provincia desestimó las presentaciones contrarias a su aplicación planteadas por la ONG "Portal de Belén” 19.

Más allá del propósito común de tales reglamentaciones -en todos los casos-, de erigirse en instrumentos desburocratizantes de los procedimientos, inspirados en la misma fuente (el fallo "F., A.L.”), son evidentes algunas diferencias respecto de las situaciones comprendidas, como los resguardos a adoptar por el médico tratante, y el establecimiento hospitalario.

Así, el Protocolo Nacional incluye deliberadamente una suerte de criterios interpretativos que, bajo la aparente intención de precisar supuestos, amplía equívocamente la casuística y los criterios permisivos, priorizando exageradamente la determinación de la gestante por sobre cualquier necesaria evaluación del profesional médico, relativa a la causal invocada por ésta. Y también lo hace respecto de las ineludibles disquisiciones jurídicas que el tema reviste.

\footnotetext{
${ }_{17}$ Fuente: https://www.telam.com.ar/notas/201912/416154-provincias-que-adhieren-al-protocolopara-la-interrupcion-legal-del-embazo.html

18 Ver texto completo en https://prensa.cba.gov.ar/salud-2/aborto-no-punible-guia-deprocedimiento/

19 Ver resolución citada en https://www.justiciacordoba.gob.ar/JusticiaCordoba/Inicio/indexDetalle.aspx?codNovedad=11889

\begin{tabular}{llll}
\hline REVISTA DE LA FACULTAD & NUMERO 3 & 2020 & Página 98 \\
\hline
\end{tabular}
} 
Ello se percibe, manifiesta y especialmente, con relación a la eximente de punibilidad basado en la causa de justificación "peligro para la vida o la salud de la mujer" (art. 86 inc. $1^{\circ}$ C. Penal), en cuanto con cita de la Organización Mundial de la Salud y el Pacto Internacional de Derechos Económicos, Sociales y Culturales, interpreta el término "salud" en sentido amplio, es decir, considerando -que aquí debe ser entendida como un "completo estado de bienestar físico, psíquico y social, y no solamente la ausencia de enfermedades o afecciones", y como "el derecho de todas las personas a disfrutar del más alto nivel posible de salud física y mental, así como el deber de los estados partes de procurar su satisfacción...” ${ }^{20}$.

Seguidamente, continúa sosteniendo que "Una interpretación adecuada... supone entender, además, su vinculación con los conceptos de bienestar y determinantes sociales de la salud, en el marco de los derechos sexuales y los derechos reproductivos como derechos humanos...”; y agrega: "El peligro para la salud debe ser entendido como la posibilidad de afectación de la salud. No requiere la constatación de una enfermedad y, en este sentido, no debe exigirse tampoco que el peligro sea de una intensidad determinada. Bastará con la potencialidad de afectación de la salud para determinar el encuadre como causal de no punibilidad para el aborto. El concepto de peligro no exige la configuración de un daño, sino su posible ocurrencia...” ${ }^{21}$ (los destacados corresponden al texto original).

La interpretación amplia que se postula, obviamente lleva a la posibilidad de admitir como permitidas -laxamente-, conductas que por la legislación penal -en tanto delictivas- están claramente prohibidas, y tan sólo eximidas de punición, en situaciones extremas. De hecho, a este supuesto de excepcionalidad se lo ha denominado "aborto terapéutico", inspirado en el propósito de habilitar una opción extrema y dirimente para salvar la vida o la salud de la embarazada, amenazadas

\footnotetext{
${ }^{20}$ Ver Protocolo nacional citado en nota 15, pauta 2.a).

${ }^{21}$ Ver Protocolo nacional citado en nota 15, apartado 3, "Circunstancias que habilitan la interrupción legal del embarazo", “Causal Salud”.
} 
LA OBJECIÓN DE CONCIENCIA MÉDICA E INSTITUCIONAL

EN CASOS DE ABORTOS NO PUNIBLES. DERIVACIONES

DEL FALLO "F.,A.L." DE LA CORTE SUPREMA DE JUSTICIA

DE LA NACIÓN

gravemente por la gestación en curso, y en las que la única alternativa médica conducente es quitar la vida al por nacer.

Salvo que se interprete sesgada y descontextualizadamente la norma, y que se desconozca o prescinda del bien jurídico que se pretende amparar mediante una conminación punitiva, en la figura del art. 86 del Código Penal (la vida del nasciturus), lejos ha estado de la intención del legislador nacional, contemplar alternativas exculpantes de responsabilidad penal a la mujer que decide abortar y a quien colabore con dicho propósito, cuando no se dan las graves circunstancias que lo justifiquen.

Extender exageradamente tal entendimiento, equivale lisa y llanamente a derogar la figura, al dar lugar a la posibilidad de que cualquier mujer que cursa un embarazo que no desea, esté habilitada para solicitar y hasta exigir la práctica de un aborto, con sólo aducir que el mismo -y/o el alumbramiento consecuente-, podrían potencialmente afectar sus personales expectativas de bienestar general, o de salud física y mental. Ello, claro está, a costa de la vida de otro ser, por caso, totalmente indefenso.

Ni el pronunciamiento citado del máximo Tribunal de la República, pese a realizar una intelección minuciosa de la norma, se expidió en ningún momento, de manera expresa, en el sentido que lo sugiere la guía en análisis. Es decir, permitiendo equiparar un embarazo forzado, a un embarazo no deseado.

En otro orden, siendo necesariamente un profesional de las ciencias médicas quien debe practicar el aborto que se solicita, el Protocolo Nacional considera que quien intervenga, es el responsable de evaluar los riesgos a la salud invocados por la gestante. $\mathrm{Y}$ aunque consiente que a estos fines pueda trabajar con equipos interdisciplinarios dispone de manera expresa, que "no es necesaria la intervención de más de una/un médica/o para la constatación de las causales de no punibilidad previstas en la ley...”, y que, “Ante la constatación de 
LA OBJECIÓN DE CONCIENCIA MÉDICA E INSTITUCIONAL EN CASOS DE ABORTOS NO PUNIBLES. DERIVACIONES

DEL FALLO "F.,A.L." DE LA CORTE SUPREMA DE JUSTICIA DE LA NACIÓN

un peligro para la salud psicosocial de la mujer, el/la médico/a tratante podrá, si lo estima necesario, realizar una interconsulta con un profesional del campo de la salud mental y/o del trabajo social, según el caso...", pero dejando aclarado que "Esta interconsulta nunca puede ser un requisito para el acceso a la práctica sino solo un apoyo para que el/la médico/a tratante evalúe la situación y detalle la causal en la HC...” 22

Como se ve, omite el protocolo considerar la eventualidad de que el médico (sobre quien recae toda la responsabilidad) estime técnica y profesionalmente la inviabilidad de la realización del aborto. ¿Qué pasaría si entiende que el embarazo no representa un peligro para la vida o la salud de la mujer que lo solicita? ¿Está dentro de la órbita de sus disquisiciones poder concluir que no se dan las condiciones eximentes de responsabilidades (la de la mujer y la suya)? ¿Qué pasaría si incluso (por lo avanzado de la gestación, o por otras dolencias) lo peligroso es justamente realizar el aborto?

En la Guía de Córdoba, donde claramente se consideran estas prácticas como "excepcionales", se aclara específicamente que su regulación tiene el propósito de "resguardar los derechos de las mujeres que requerían dicha práctica, como así también el de los profesionales del equipo de salud". Y no sólo se amplía el espectro de evaluaciones médicas posibles y se facilita el acceso del profesional al asesoramiento que estime necesario para una correcta valoración médico-legal, sino que además se atiende a sus posibles derivaciones y disyuntivas de manera expresa. Establece sobre el particular: "El peligro para la vida o para la salud debe ser constatado por el médico tratante y sobre la base de los estándares vigentes quien, de considerarlo necesario, podrá convocar un equipo interdisciplinario con los profesionales que requiera el caso debiendo determinar, además, la inexistencia de otro tratamiento alternativo, como así también que el peligro para la vida o la salud es consecuencia del embarazo o que el mismo contribuye a agravar dicho peligro...”. Y respecto de la potencial

${ }^{22}$ Ver Protocolo nacional citado en nota 15, apartado 5, "Los equipos de salud".

REVISTA DE LA FACULTAD

2020

Página 101 
inconveniencia de su concreción, también prevé que "En el supuesto de que, a juicio del profesional interviniente, no sea posible realizar el aborto, ello deberá ser puesto en conocimiento de la mujer o de su representante legal, por escrito, inmediatamente, dejándose constancia en la Historia Clínica de tal circunstancia...” ${ }^{23}$ (los destacados me pertenecen).

En definitiva, como también se postula en el fallo, el profesional tratante -de acuerdo a su arte y su ciencia- es quien debe discernir todas las cuestiones inherentes a la viabilidad de la interrupción de un embarazo que se le solicita, siempre en el marco de las situaciones comprendidas en los supuestos del art. 86 del Código Penal24. Y también es él, quien debe relevar si se dan en el caso concreto "las condiciones médicas e higiénicas necesarias" para llevar a cabo el aborto "de manera rápida, accesible y segura" 25 ; de donde, ante la ausencia de las condiciones, o la insuficiencia de esas garantías, no debe realizarlo, por no existir riesgos para la salud o la propia vida de quien lo reclama atribuibles al embarazo, o por no darse las condiciones exigidas para su materialización.

\section{La responsabilidad de los profesionales de la salud ante la solicitud de realización de un aborto no punible.}

4.a) Alcances del deber médico de atención a la solicitante del aborto.

Las prescripciones indicadas por la C.S.J.N., no devienen de aplicación automática ni estrictamente obligatorias para cualquier facultativo, toda vez que resulta obvio que existen especialidades médicas cuyas prácticas se fundan en previas

\footnotetext{
23 Ver Resolución del Ministerio de Salud de la Provincia de Córdoba ${ }^{\circ}$ 093/12 y su anexo en https://prensa.cba.gov.ar/salud-2/aborto-no-punible-guia-de-procedimiento/

24 C.S.J.N. en "F., A.L.", considerando 22 in fine: "Si concurren las circunstancias que permiten la interrupción del embarazo, es la embarazada que solicita la práctica, junto con el profesional de la salud, quien debe decidir llevarla a cabo y no un magistrado a pedido del médico...". 25 C.S.J.N. en "F., A.L.”, considerando 25: “...es el Estado, como garante de la administración de la salud pública, el que tiene la obligación, siempre que concurran las circunstancias que habilitan un aborto no punible, de poner a disposición, de quien solicita la práctica, las condiciones médicas e higiénicas necesarias para llevarlo a cabo de manera rápida, accesible y segura...”.
} 
LA OBJECIÓN DE CONCIENCIA MÉDICA E INSTITUCIONAL

EN CASOS DE ABORTOS NO PUNIBLES. DERIVACIONES

DEL FALLO "F.,A.L." DE LA CORTE SUPREMA DE JUSTICIA

DE LA NACIÓN

capacitaciones y habilitaciones específicas. Y no es dable suponer que, toda persona que se gradúa como médico o auxiliar de la medicina, cuente, por esa sola circunstancia, con los conocimientos, aptitud y experticia indispensables para llevar adelante o colaborar en una práctica abortiva que -a no dudarlo-, se materializa normalmente mediante ataques medicamentosos o intrusiones traumáticas en el útero de una mujer.

De manera que un mandato legal que así lo presuma, parte ab initio de un error de concepción y de criterio que -incluso- iría en contra del mismo propósito de la norma que lo autoriza (preservar la salud de la gestante).

Idéntica consideración cabe respecto de un establecimiento hospitalario que, por distintas razones puede no contar con los servicios, personal, instrumental o autorización necesarios para ejecutarla, evitando o descartando potenciales riesgos para la salud de las pacientes. Esa parece haber sido la razón por la que el fallo circunscribe su recomendación a las autoridades públicas, para que "toda institución que atienda a las situaciones aquí examinadas" (entiéndase, que cuente con servicios de obstetricia y ginecología) cuente con "recursos humanos suficientes para garantizar, en forma permanente, el ejercicio de los derechos que la ley le confiere a las víctimas de violencia sexual" ${ }^{26}$. (el destacado me pertenece).

Pero aún dejando de lado dicha circunstancia, la cuestión también lleva a considerar si, obviando los obstáculos que representan tanto la carencia de recursos técnicos suficientes, como la ausencia de profesionales debidamente formados y entrenados, es dable imponer (imperativo legal mediante) a quienes sí lo estén, el deber de practicar abortos, si por razones de otra índole, que pasan por las más profundas, íntimas y legítimas convicciones, sus principios morales y sus valores (que normalmente coinciden con los que determinaron su vocación), semejante carga, implica la obligación de obrar en contra de lo que los impulsó a

${ }^{26}$ C.S.J.N. en “F., A.L.”, considerando ${ }^{\circ}$ 29, in fine. 
LA OBJECIÓN DE CONCIENCIA MÉDICA E INSTITUCIONAL

EN CASOS DE ABORTOS NO PUNIBLES. DERIVACIONES

DEL FALLO "F.,A.L." DE LA CORTE SUPREMA DE JUSTICIA

DE LA NACIÓN

formarse y juraron hacer con su ciencia (salvar vidas), o en conciencia, asumen como prohibido, con independencia de si prestan sus servicios en establecimientos públicos o privados.

Es que, sin entrar al enconado debate de fondo que en definitiva subyace sobre toda esta problemática (v.gr.: si la legislación puede cambiar, y admitir libremente el aborto consentido de la gestante, sin confrontar con el plexo normativo de máxima jerarquía de nuestro País), no se puede negar que, aún presentándosela como una práctica discutida que, mediante el argumento de priorizar la salud de la mujer gestante (entendida incluso como cualquier circunstancia con capacidad de alterar su bienestar), opta por la privación de la vida del niño o niña por nacer. Semejante "terapia", aunque no lo sea para quien lo solicita, sin dudas involucra un grave conflicto ético para el responsable de llevarlo a cabo, cuando, fuera de los casos de real emergencia médica, sus propias convicciones se lo impiden.

En este aspecto, en consideración al valor de estas últimas, se ha dicho que "la objeción de conciencia no es, ni mucho menos, un acto revolucionario o de oposición al sistema: es todo lo contrario, un deber de defensa del sistema jurídico, de protección y promoción de su más auténtico deber ser...”. ${ }^{27}$

Es claro que el máximo Tribunal nacional en el fallo apuntado, ratificó amplia y explícitamente la posibilidad de invocar dicho derecho, no tan sólo a los médicos, sino a todo el "personal sanitario".

Pero lo hizo condicionándolo a que el sistema previsto permita anticipar su posicionamiento personal "en el momento de la implementación del protocolo o al inicio de las actividades en el establecimiento de salud correspondiente", de manera que no haya lugar a "derivaciones o demoras que comprometan la

${ }_{27}$ SARTEA, Claudio, en "¿Qué objeción? ¿qué conciencia? reflexiones acerca de la objeción de conciencia y su fundamentación conceptual”, ya citado en nota 2 , en http://aebioetica.org/revistas/2013/24/82/391.pdf; p. 394 
LA OBJECIÓN DE CONCIENCIA MÉDICA E INSTITUCIONAL

EN CASOS DE ABORTOS NO PUNIBLES. DERIVACIONES

DEL FALLO "F.,A.L." DE LA CORTE SUPREMA DE JUSTICIA

DE LA NACIÓN

atención de la requirente del servicio"28. Se trata entonces de un reconocimiento sesgado, por cuanto exige que la objeción se exteriorice en un único momento, por única vez, para todos y para siempre.

Con acierto se ha dicho al respecto: "Curiosa forma de inmovilizar la conciencia, ya que si con el correr del tiempo, quizás después de practicar varios abortos, quizás tras una nueva reflexión ética o religiosa, el profesional replantease sus pautas morales, se vería imposibilitado de ser atendido y respetado. Esta restrictiva visión de lo que es la objeción de conciencia 'impropia' (en tanto determinada anticipadamente por una norma o se haya, como aquí, 'judicializado') ciertamente no invalida la que es 'propia', cuando la persona tiene la necesidad de conformar su actuar a imperativos de conciencia aunque sea 'contra legem', que es el supuesto más analizado por la doctrina y jurisprudencia”29.

Es que si bien se apunta a evitar la discrecionalidad del médico que bajo el amparo de la objeción, pretenda encubrir otras motivaciones personales reñidas con sus deberes éticos y profesionales, desconoce que efectivamente no sólo el médico, sino cualquier persona, producto de la maduración de sus ideas y experiencias de vida, goza del derecho humano de tener sus propias convicciones, y también de repensarlas, adaptarlas o modificarlas, y de obrar en consecuencia.

Particularmente, las cuestiones de conciencia, normalmente fundadas en reflexiones serias y responsables, son personales, íntimas, y están siempre presentes en todo ser humano. Y por su propia naturaleza, pueden verse afectadas por cambios de criterio, de actitud, o hasta hacer incurrir a las personas en conductas contradictorias con otras suyas anteriores, de donde, lo que en un

\footnotetext{
${ }^{28}$ C.S.J.N. en "F., A.L.", considerando $\mathrm{n}^{\circ} 29$.

29 Padilla, Norberto, en Anuario del Centro de Derecho Constitucional No 4, 2016 de la Universidad Católica Argentina, en https://repositorio.uca.edu.ar/bitstream/123456789/2583/1/objecionconciencia-aborto-padilla.pdf
} 
momento le haya parecido moralmente aceptable, luego pase a no serlo, o viceversa.

No son pocos los ejemplos que pueden darse sobre personas que tuvieron cambios radicales en su posicionamiento personal frente al aborto. Los hay tanto de quienes se los hicieron practicar (Abby Johnson30, Patricia Sandoval31), como de quienes los practicaban profesionalmente (Bernard Nathanson32, Anthony Levatino33, John Bruchalski34, entre muchos otros, por citar notorios casos dados en países donde el aborto está permitido con amplitud y desde hace mucho tiempo).

Si de lo que se trata, es de evitar o impedir que el profesional asuma conductas ambiguas, arbitrarias o sorpresivas, que responden a criterios de selección coyunturales o discrecionales con incumplimiento de su deber de asistencia a la paciente, en tanto ello pueda implicar una dilación injustificada (o una maniobra tendiente a ese fin), la conminación podría ser atendible.

Pero una situación así, más allá de las derivaciones deontológicas o legales a que pueda dar lugar la arbitrariedad del médico, sólo cobraría potencialidad dañosa y entidad dirimente, en caso de tratarse el servicio requerido a dicho profesional, del único disponible por no poderse acudir, sin demoras riesgosas o irreversibles, a otras alternativas médicas u hospitalarias aptas.

\section{4.b) La objeción de conciencia de los profesionales de la salud en} los protocolos y guías para los casos de aborto no punible.

Las conminaciones del art. 86 del Código Penal (y sus eximentes) involucran expresamente a la mujer encinta que se practique o haga practicar un aborto, como también al profesional del arte de curar que lo facilite o practique. De manera que

${ }^{30}$ https://es.wikipedia.org/wiki/Abby Johnson

${ }^{31}$ https://es.wikipedia.org/wiki/Patricia Sandoval

$3^{2}$ https://www.lanacion.com.ar/opinion/el-grito-silencioso-del-aborto-nid1687935/

33 https://es.wikipedia.org/wiki/Anthony Levatino

34 https://www.actuall.com/vida/el-nuevo-doctor-nathanson-john-bruchalski-de-practicar-

abortos-a-dirigir-la-mayor-clinica-provida-en-virginia/ 
LA OBJECIÓN DE CONCIENCIA MÉDICA E INSTITUCIONAL

EN CASOS DE ABORTOS NO PUNIBLES. DERIVACIONES

DEL FALLO “F.,A.L." DE LA CORTE SUPREMA DE JUSTICIA

DE LA NACIÓN

tanto porque se encuentra con la capacidad de poder hacerlo, como porque se considere que tiene el deber de hacerlo -como se propugna en el fallo "F., A.L."-, es imprescindible para los médicos tener claro ambas situaciones.

Y más allá de las disquisiciones médico-legales que obligadamente deban realizar, es dable reconocer que, por lo general, muchos de ellos encuentran serios y atendibles reparos personales para llevar a cabo la interrupción de un embarazo. Como se dijo, a veces por no haber adquirido la especialización y habilitación necesarias, otras, por constituir una práctica reñida con sus principios éticoprofesionales, y con su cometido vocacional: "salvar vidas”.

Alertados de la sensibilidad que tiene el tema para los facultativos (como para la sociedad toda), pero admitiéndolos como los únicos autorizados para materializarlo en los casos previstos en el art. 86 del Código Penal, el máximo tribunal nacional reconoció en sus considerandos la objeción de conciencia como una razón válida para exceptuarse de concretarlo, estableciendo que “deberá disponerse un adecuado sistema que permita al personal sanitario ejercer su derecho de objeción de conciencia sin que ello se traduzca en derivaciones o demoras que comprometan la atención de la requirente del servicio”, pero en tales casos, "deberá exigirse que la objeción sea manifestada en el momento de la implementación del protocolo o al inicio de las actividades en el establecimiento de salud correspondiente, de forma tal que toda institución que atienda a las situaciones aquí examinadas cuente con recursos humanos suficientes para garantizar, en forma permanente, el ejercicio de los derechos que la ley le confiere a las víctimas de violencia sexual" 35.

El Protocolo nacional avanza sobre lo expresado en el fallo y sintetiza otras derivaciones que son fruto de la personal interpretación de sus redactores y firmantes.

35 C.S.J.N. en “F.,A.L.”, considerando 29. 
LA OBJECIÓN DE CONCIENCIA MÉDICA E INSTITUCIONAL

EN CASOS DE ABORTOS NO PUNIBLES. DERIVACIONES

DEL FALLO "F.,A.L." DE LA CORTE SUPREMA DE JUSTICIA

DE LA NACIÓN

Ello ocurre cuando por ejemplo, entiende que "La objeción puede ser invocada respecto a realizar la práctica concreta de la ILE, pero no para las acciones necesarias para garantizar la atención integral, sean previas o posteriores a la interrupción (por ejemplo: ecografías, toma de tensión arterial, etc.). Estas acciones no tienen como finalidad interrumpir la gestación y se realizan de forma complementaria a un gran número de prácticas de salud para garantizar la salud integral y, por tanto, no puede existir conflicto moral o religioso con su realización en profesionales dedicados al cuidado de la salud..." ${ }^{6}$

El sentido de la prescripción reglamentaria impone a todo médico o auxiliar de la medicina, amparados por la objeción de conciencia, participar (en el sentido literal y jurídico del término) del acto médico reñido con sus principios, y facilitar de ese modo, directa o indirectamente, la concreción del aborto por otro profesional. En una comparación burda pero efectiva, sería como obligar a un vegetariano a matar una vaca (o colaborar con otro para que lo haga), aunque sus convicciones le impidan alimentarse de ella.

Pero la reglamentación va más allá y le ordena al profesional hasta "comer la vaca", si no hay otra persona "carnívora", que lo pueda hacer, cuando establece que "No podrá ejercerse la objeción de conciencia si no existiera un/a profesional disponible para la (sic) realizar la práctica de forma oportuna, tal y como lo establecen las leyes de derechos del pacientes y de ejercicio de la medicina (Ley 26.529, artículo 2.a; Ley 17.132, artículo 19.2)...” 37

La invocación de la primer norma citada (Ley 26.529), no es atinente, ni su aplicación es pertinente, porque aquí no se trata de desatender -en rigor- a una "paciente" por razón de las "ideas, creencias religiosas, políticas, condición socioeconómica, raza, sexo, orientación sexual o cualquier otra condición” que le

\footnotetext{
36 Ver Protocolo nacional citado en nota 15, apartado 5, "Los equipos de salud", "Objeción de conciencia”, $5^{\circ}$ párrafo.

37 Ver Protocolo nacional, citado en nota 15, apartado 5, "Los equipos de salud”, "Objeción de conciencia", $8^{\circ}$ párrafo.
} 
comprendan ${ }^{38}$, sino por los conocimientos y convicciones propias del médico, quien sí en cambio está obligado (las tenga o no) a realizar una evaluación conforme a su ciencia sobre si se dan o no en el caso las circunstancias médicas y legales eximentes de responsabilidad penal para él y para la mujer que se presenta a requerirle sus servicios (que no necesariamente por ello, la convierte en rigor en "paciente"), como también las que tienen que ver con sus personales reparos éticos para intervenir de cualquier manera en el acto.

Es que, si cabe la figura, por más que se tenga conocimientos sobre armas de fuego, no se puede obligar a alguien que no está de acuerdo con la pena de muerte, a integrar un pelotón de fusilamiento, ni a cargar el arma del fusilero.

La segunda norma, en cambio (Ley 17.132), alude a una situación distinta, en tanto se refiere a la gravedad del cuadro que presenta una persona "enferma", que requiere su atención, hipótesis que -no se discute-, impone la asistencia médica obligatoria, y de la que el profesional no se puede exceptuar mientras no la pueda delegar en otro profesional 39. Es obvio que si la situación se presenta como una emergencia (en el sentido médico de la palabra), la atención siempre se impone.

La Guía de Córdoba, por su parte, no tiene el carácter conminatorio de la anterior y es respetuosa del derecho del facultativo a plantear su impedimento, sin restricciones ni condicionamientos, al establecer que " $E$ n caso de que el médico tratante fuera a hacer uso del derecho de objeción de conciencia, deberá hacer saber dicha

\footnotetext{
${ }^{8}$ Ley 25.529, art. $2^{\circ}$ inc. a: "Derechos del paciente. Constituyen derechos esenciales en la relación entre el paciente y el o los profesionales de la salud, el o los agentes del seguro de salud, y cualquier efector de que se trate, los siguientes: a) Asistencia. El paciente, prioritariamente los niños, niñas y adolescentes, tiene derecho a ser asistido por los profesionales de la salud, sin menoscabo y distinción alguna, producto de sus ideas, creencias religiosas, políticas, condición socioeconómica, raza, sexo, orientación sexual o cualquier otra condición. El profesional actuante sólo podrá eximirse del deber de asistencia, cuando se hubiere hecho cargo efectivamente del paciente otro profesional competente...”.

39 Ley 17.132, artículo 19.2: “...Los profesionales que ejerzan la medicina están, sin perjuicio de lo que establezcan las demás disposiciones legales vigentes, obligados $a: \ldots 2^{o}$ ) asistir a los enfermos cuando la gravedad de su estado así lo imponga y hasta tanto, en caso de decidir la no prosecución de la asistencia, sea posible delegarla en otro profesional o en el servicio público correspondiente...”.
} 
LA OBJECIÓN DE CONCIENCIA MÉDICA E INSTITUCIONAL

EN CASOS DE ABORTOS NO PUNIBLES. DERIVACIONES

DEL FALLO “F.,A.L." DE LA CORTE SUPREMA DE JUSTICIA

DE LA NACIÓN

circunstancia al Director del Hospital donde presta servicio, inmediatamente después de haber tomado conocimiento de la solicitud de la paciente y en ningún caso podrá aparejar demoras que comprometan la atención de la requirente del servicio. Dicha objeción deberá instrumentarse por escrito, dejando constancia que la misma lo es tanto para realizar las prácticas abortivas en el ámbito público como en el privado. La misma deberá ser archivada por la autoridad del Hospital, quien deberá informar a la Secretaría de Atención Médica del Ministerio de Salud..." 40. Se trata de una clara (y necesaria) previsión que no conspira contra la posibilidad de la solicitante de acceder a la práctica, sino que determina su vehiculización hacia quien no se considera médica y moralmente inhibido, impedido o en desacuerdo con ella.

Sin desmedro de los derechos de la mujer, se destaca que en el reglamento el respeto al profesional es amplio, permanente, y se complementa con la prohibición de estigmatizarlo por sus convicciones, al prescribirse que "Bajo ninguna circunstancia dicha objeción podrá traer aparejada sanciones de ningún tipo. El objetor podrá en cualquier momento dejar sin efecto la objeción con una nueva manifestación por escrito". ${ }^{41}$

Para la dilucidación de los casos, la normativa transfiere la responsabilidad de la atención requerida a la institución hospitalaria, estableciendo sea ésta la que "inmediatamente de conocida la objeción de conciencia planteada, deberá arbitrar los medios para organizar el servicio en aras de garantizar la atención de la paciente. Para el supuesto de que en esa institución no cuente con otro médico que pueda realizar las prácticas abortivas del caso, deberá poner en conocimiento esta circunstancia a la Secretaría de Atención Medica del Ministerio

\footnotetext{
40 Art. 3.1-c.1) de la Guía de procedimiento para la atención de pacientes que soliciten prácticas de aborto no punible, según lo establecido en el artículo 86 incisos $1^{\circ}$ y $2^{\circ}$ del Código Penal de la Nación, citada en nota 18.

${ }^{41}$ Art. 3.1.-c.3), de la Guía de procedimiento para la atención de pacientes que soliciten prácticas de aborto no punible, citada en nota 18.
} 
LA OBJECIÓN DE CONCIENCIA MÉDICA E INSTITUCIONAL

EN CASOS DE ABORTOS NO PUNIBLES. DERIVACIONES

DEL FALLO "F.,A.L." DE LA CORTE SUPREMA DE JUSTICIA

DE LA NACIÓN

de Salud de la Provincia, quien deberá arbitrar los medios para garantizar la prestación en cuestión...” 42

La previsión normativa, tiene perfecta armonía con las consideraciones realizadas por los propios médicos desde la Academia Nacional de Medicina, cuando señalaron que "Todas las leyes nacionales y provinciales que rigen el ejercicio de la profesión en nuestro país dictan normas, obligaciones, prohibiciones, sanciones, etc., pero de ninguna manera mencionan los derechos de los médicos...”, respecto de lo cual reclaman desde dicho ámbito científico su derecho "a actuar en el ejercicio de la profesión con total libertad de conciencia acorde con la ética y conocimientos científicos...”. Ello implica (según se menciona en el mismo documento) que, siendo la objeción de conciencia "un testimonio pacífico y apolítico por el cual un médico puede no ejecutar un acto reglamentariamente permitido, sin que ello signifique el rechazo de la persona y el abandono del paciente...", puede rechazar la atención que le es requerida cuando "le exige realizar un procedimiento que el médico, por razones científicas y/o éticas, considera inadecuado o inaceptable...", si "considera que este acto se opone a sus convicciones morales. En tal sentido, la Academia Nacional de Medicina aboga por el derecho de los médicos a actuar en el ejercicio de la profesión con total libertad de conciencia acorde con la ética y conocimientos científicos”. 43

La defensa de este derecho, los médicos la reiteraron en tono crítico al tratarse el proyecto de ley de despenalización del aborto en el que se les pretendió imponer en

\footnotetext{
42 Art. 3.1.-c.2), de la Guía de procedimiento para la atención de pacientes que soliciten prácticas de aborto no punible, citada en nota 18.

43 Declaración del 28 de setiembre de 2000, de la Academia Nacional de Medicina, https://anm.edu.ar/wp-content/uploads/2018/o7/Objeci\%C3\%B3n-de-conciencia.pdf; posición que mantuvo en declaración del 30 de setiembre de 2010 en https://anm.edu.ar/wpcontent/uploads/2018/o7/Consideraciones-sobre-el-aborto.pdf; y reafirmó con posterioridad al fallo "FAL", en respuesta a la edición del 2015 del Protocolo Nacional para la atención integral de las personas con derecho a la interrupción legal del embarazo, en www.acamedbai.org.ar; y en la Sesión Privada del Plenario Académico del 30 de julio de 2015, en https://anm.edu.ar/wpcontent/uploads/2018/07/ABORTOYOBJECIONDECONCIENCIA.pdf
} 
LA OBJECIÓN DE CONCIENCIA MÉDICA E INSTITUCIONAL

EN CASOS DE ABORTOS NO PUNIBLES. DERIVACIONES

DEL FALLO “F.,A.L." DE LA CORTE SUPREMA DE JUSTICIA

DE LA NACIÓN

tono imperativo y conminatorio la práctica de abortos 44 . Y desde el ámbito jurídico, en la misma ocasión, también merecieron similar enfático acompañamiento, por parte de un numeroso colectivo de profesionales del derecho, con fundamentos legales sólidos y explícitos, al denunciar que dicho proyecto "obliga aun a los objetores de conciencia a realizar abortos en caso de peligro a la vida o la salud de la mujer y que requieran atención médica inmediata e impostergable. Tanto los conceptos 'inmediato' e 'impostergable' en el ámbito de la medicina como la definición de 'salud' por parte de la Organización Mundial de la Salud (OMS), permitirían calificar como incumplimiento contractual y/o acto ilícito del profesional de la salud a toda omisión de intervenir por parte de los objetores de conciencia. En efecto, a partir de esa concepción amplia de 'salud', todo 'embarazo no deseado' pondría en peligro la salud psíquica y social de la persona gestante y requeriría atención médica inmediata e impostergable, más aún, considerando que la práctica abortiva tiene que llevarse a cabo en un plazo máximo de cinco (5) días conforme lo exige el art. 11 del Proyecto de Ley...”. 45

No se trata de promover que los profesionales de la salud, eludan sus responsabilidades profesionales una vez enfrentados ante la situación fáctica que les determina a actuar (que es lo que pretende desalentar la CSJN)46. Se trata de reconocer que el criterio médico es gravitante a la hora de definir, no sólo la viabilidad del embarazo o la necesidad de su interrupción, sino su obligación legal de hacerlo, desaconsejarlo, o hasta no practicarlo, aunque derivándolo a otro profesional o institución hospitalaria.

$\mathrm{Al}$ respecto se dijo en el fallo "F., A.L.": "Si concurren las circunstancias que permiten la interrupción del embarazo, es la embarazada que solicita la práctica,

44 Véase declaración del 22 de marzo de 2018, en https://anm.edu.ar/wpcontent/uploads/2018/07/1.pdf;

45 Nota del 25 de junio de 2018 presentada a los Senadores nacionales, en https://www.impulsobaires.com.ar/amp/265578/abogados_a_los_senadores_la_ley_de_aborto_ es_groseramente_inconstitucional/

${ }^{46}$ C.S.J.N. en "F., A.L.”, considerando $22^{\circ}$. 
LA OBJECIÓN DE CONCIENCIA MÉDICA E INSTITUCIONAL

EN CASOS DE ABORTOS NO PUNIBLES. DERIVACIONES

DEL FALLO “F.,A.L." DE LA CORTE SUPREMA DE JUSTICIA

DE LA NACIÓN

junto con el profesional de la salud, quien debe decidir llevarla a cabo y no un magistrado a pedido del médico 47.

4.c) La objeción de conciencia institucional en los protocolos y guías para los casos de aborto no punible.

El decisorio que encabeza el presente, en sus exhortaciones finales a las autoridades nacionales y provinciales, establece que "deberá disponerse un adecuado sistema que permita al personal sanitario ejercer su derecho de objeción de conciencia sin que ello se traduzca en derivaciones o demoras que comprometan la atención de la requirente del servicio...", a cuyo fin "deberá exigirse que la objeción sea manifestada en el momento de la implementación del protocolo o al inicio de las actividades en el establecimiento de salud correspondiente, de forma tal que toda institución que atienda a las situaciones aquí examinadas cuente con recursos humanos suficientes para garantizar, en forma permanente, el ejercicio de los derechos que la ley le confiere a las víctimas de violencia sexual”. 48

La transcripción precedente destaca que la objeción es reconocida como un derecho del que goza el "personal sanitario", lo que autoriza -ya se dijo- a considerar comprendidos tanto a médicos, como a anestesistas, personal de enfermería, etc. Pero claramente se lo hace desde el entendimiento que el reparo ético es uno de los obstáculos y barreras a allanar para que los abortos puedan practicarse, motivo por el cual, dado que "toda institución" que atienda embarazos y partos está obligada a contar con los medios humanos y técnicos, la llamada "objeción de conciencia institucional" podría no estar contemplada.

Este principio sin embargo, es claramente violatorio de la libertad de conciencia para los responsables de establecimientos de carácter confesional o que tengan un ideario determinado incompatible con el aborto.

47 C.S.J.N. en "F., A.L.", considerando $22^{\circ}$ in fine.

48 C.S.J.N. en "F., A.L.", considerando 29.

REVISTA DE LA FACULTAD

2020

Página 113 
LA OBJECIÓN DE CONCIENCIA MÉDICA E INSTITUCIONAL

EN CASOS DE ABORTOS NO PUNIBLES. DERIVACIONES

DEL FALLO "F.,A.L." DE LA CORTE SUPREMA DE JUSTICIA

DE LA NACIÓN

Aunque la C.S.J.N. no lo exteriorice, el argumento que suele abonar dicha postura es que la conciencia es de las personas físicas, no de las jurídicas. Pero no puede ignorarse que son las primeras, las que gozan también del derecho de asociarse con fines lícitos, como lo es crear instituciones dotadas de un determinado ideario, que refleja las convicciones éticas o religiosas de aquéllos y configura la actividad de éstas.

No debe dejar de computarse en tal inteligencia, que los establecimientos hospitalarios en particular, y las instituciones públicas o privadas, en general, están compuestas por hombres y mujeres. $\mathrm{Y}$ aunque no puede asignárseles como entidades una concepción o ideología determinada sobre todos los temas que las involucran, sus componentes (incluyendo a sus fundadores, autoridades e integrantes, además de los profesionales médicos y auxiliares que allí se desempeñan) sí las tienen. De allí que, en el caso de las privadas, habiendo sido ideadas, creadas o fundadas, bajo la postulación de determinado objeto, o determinado propósito, consagran un ideario institucional que es coherente con el de quienes participan en ella.

Si el cometido institucional es la prestación de un servicio de salud, y éste (o su modalidad), por no ser contrario a las leyes que regulan dicha actividad, es aceptado por quienes ejercen las potestades estatales convalidantes, mal puede reprochársele o imponérsele con rigor coercitivo a quienes intervienen en su gestión, conductas que están en pugna con dicho ideario o condicionar su desenvolvimiento bajo la misma invocación. Mucho menos cuando es el Estado, desde su infraestructura y con sus recursos (y no los particulares, con los suyos), quien debe asegurar en plenitud, en estos casos, el acceso a los servicios de salud de los ciudadanos, tal como lo entiende la Corte.

El Protocolo nacional, con cita del fallo de la C.S.J.N., contiene sobre el tema una cláusula limitativa al prescribir que "La objeción de conciencia es siempre individual. Todos los efectores de salud en condiciones de practicar ILE 
LA OBJECIÓN DE CONCIENCIA MÉDICA E INSTITUCIONAL

EN CASOS DE ABORTOS NO PUNIBLES. DERIVACIONES

DEL FALLO "F.,A.L." DE LA CORTE SUPREMA DE JUSTICIA

DE LA NACIÓN

deberán garantizar su realización en los casos con derecho a acceder a la misma. Asimismo, deberán contar con recursos humanos y materiales suficientes para garantizar en forma permanente el ejercicio de los derechos que la ley les confiere a las personas en relación a esta práctica (CSJN, 2012, considerando 29)" 49 (el subrayado me pertenece). A tal punto debe garantizarse el servicio que si no hay otro médico o médica disponible, el objetor tendrá que realizarlo.

Pero es que nunca un profesional podría ser obligado a llevar a cabo un aborto porque en ese establecimiento o en ese lugar no haya otro que lo pueda o quiera realizar. Es absolutamente claro que nadie puede ser forzado a realizar lo que considera matar.

Aunque en línea con la proclamada y explícita tendencia de favorecer la realización de abortos, no deja de resultar llamativa la previsión cuando, de hecho, a favor del respeto de la objeción de conciencia institucional, en nuestro País, ya existen normas que la contemplan expresamente (aún vigentes), para situaciones mucho menos dramáticas.

En efecto, el art. 10 de la Ley 25.673 ("Programa Nacional de Salud Sexual y Procreación Responsable") admite que "las instituciones privadas de carácter confesional que brinden por sí o por terceros servicios de salud, podrán con fundamento en sus convicciones, exceptuarse de lo dispuesto en el art. 6, inciso b) de la presente ley"50.

$\mathrm{Su}$ decreto reglamentario ( $\mathrm{n}^{\circ}$ 1282/2003), con acierto, amplió los alcances de la norma en dos aspectos: a) por un lado, reconoció la posibilidad de esgrimir la objeción de conciencia "tanto en la actividad pública institucional como en la privada”; y b) añadió en lo que aquí concierne, al universo de entidades habilitadas

\footnotetext{
49 Ver Protocolo nacional citado en nota 15, apartado 5, "Los equipos de salud", "Objeción de conciencia”, último párrafo.

$5^{0}$ Véase texto citado de la Ley en

http://www.msal.gob.ar/images/stories/ryc/graficos/o000000677cnt-Leyes-que-reconocen-tusderechos.pdf;
} 
para ejercerlo ad intram, no sólo a las "confesionales" (o religiosas) a que alude la ley, sino también a otros centros de salud privados que "en base a sus fines institucionales y/o convicciones de sus titulares, optaren por ser exceptuados del cumplimiento del artículo 6 , inciso b) de la ley que se reglamenta”, imponiéndoles a cambio el deber de "derivar a la población a otros Centros asistenciales" ${ }^{51}$

Y si contribuye a visibilizar la extralimitación del protocolo que se critica, resulta oportuno comentar que en el año 2008, el Congreso de la República Oriental del Uruguay, con el voto mayoritario de los legisladores del Frente Amplio, gobernante, aprobó su ley de aborto. Pero por mensaje del 14 de noviembre, el entonces presidente, Dr. Tabaré Vázquez fundó en quince razones su decisión de vetar la ley. Una de esas razones fue la forma en que se regulaba la objeción de conciencia (XI), y lo planteó con términos severos al expresar que "el proyecto aprobado genera una fuente de discriminación injusta hacia aquéllos médicos que entienden que su conciencia les impide realizar abortos, y tampoco permite ejercer la libertad de conciencia de quien cambia de opción y decide no realizarlo más. Nuestra Constitución sólo reconoce desigualdades ante la ley cuando se fundan en los talentos y virtudes de las personas. Aquí, además, no se respeta la libertad de pensamiento de un ámbito por demás profundo e íntimo" ${ }^{2}$.

Es digno de destacar en los argumentos del hoy exmandatario uruguayo, que no se basa en motivaciones religiosas sino éticas y médicas (profesión que ejerce). Y parte de un principio, que debería repetirse una y otra vez también en la Argentina y ante el fallo "F., A.L.": "Hay consenso en que el aborto es un mal social que hay

${ }^{51}$ Fecha de Emisión: 23/05/2003; Publicado en: Boletín Oficial 26/05/2003. Ver texto completo en https://www.argentina.gob.ar/normativa/nacional/decreto-1282-2003-85450/texto;

$5^{2}$ Comentario y apreciaciones tomadas de Norberto Padilla, en Anuario del Centro de Derecho Constitucional No 4, 2016 de la Universidad Católica Argentina, en https://repositorio.uca.edu.ar/bitstream/123456789/2583/1/objecion-conciencia-abortopadilla.pdf; donde también hace referencia al análisis exhaustivo punto por punto del mensaje en: Veto al aborto, Estudios interdisciplinarios sobre las 15 tesis del Presidente Tabaré Vázquez. Facultad de Derecho, Universidad de Montevideo, Montevideo, 2013. El capítulo Veto a la limitación de la libertad de conciencia (pág. 121) a cargo de la Dra. Carmen Asiain Pereira, Profesora de Derecho y Religión, Universidad de Montevideo y actual Presidenta del Consorcio Latinoamericano de Libertad Religiosa. 
que evitar".

Luego, bajo la presidencia de José Mujica, se sancionó la ley 18.897 de "Interrupción Voluntaria del Embarazo", cuyo decreto reglamentario ( $\mathrm{n}^{\circ}$ 375/12) limitó gravitantemente el derecho a la objeción de conciencia. No obstante, un grupo de médicos ginecólogos planteó ante el Tribunal de lo Contencioso Administrativo una acción de nulidad contra varios artículos del decreto, demanda que fue acogida en casi en su totalidad, anulándolos. Entre otras razonadas consideraciones, el tribunal oriental concluyó, en lo que aquí interesa, que "un profesional no podría ser obligado a llevar a cabo un aborto porque en ese establecimiento o en ese lugar no haya otro que lo pueda o quiera realizar. En este caso extremo, es claro que nadie puede ser forzado a matar". 53

En el orden provincial, la guía vigente no contiene prescripciones semejantes a la de la Nación, en tanto más que imposiciones, contempla alternativas que tienden a resolver la inexistencia de profesionales dispuestos a practicar los abortos.

En tal sentido establece que "La autoridad de la institución involucrada, inmediatamente de conocida la objeción de conciencia planteada (por su personal), deberá arbitrar los medios para organizar el servicio en aras de garantizar la atención de la paciente...”. Y agrega que en la eventualidad que “...en esa institución no cuente con otro médico que pueda realizar las prácticas abortivas del caso, deberá poner en conocimiento esta circunstancia a la Secretaría de Atención Medica del Ministerio de Salud de la Provincia, quien deberá arbitrar los medios para garantizar la prestación en cuestión”.54

Surge claramente que no existe el propósito de obligar a ningún profesional a que

\footnotetext{
53 Asiain Pereira, Carmen, Objeción de Conciencia. Tribunal de máximo rango anula con efectos generales y absolutos decreto que la restringía, en Revista de Derecho Público, noviembre de 2015, $\mathrm{N}^{0}$ 48, en www.revistaderechopublico.com/revistas/48/ asiain.php\#reft46; citada por Norberto Padilla en el artículo mencionado anteriormente.

54 Art. 3.1.-c.2) de la Guía de procedimiento para la atención de pacientes que soliciten prácticas de aborto no punible, según lo establecido en el artículo 86 incisos $1^{\circ}$ y $2^{\circ}$ del Código Penal de la Nación; citada en nota 18.
} 
LA OBJECIÓN DE CONCIENCIA MÉDICA E INSTITUCIONAL

EN CASOS DE ABORTOS NO PUNIBLES. DERIVACIONES

DEL FALLO "F.,A.L." DE LA CORTE SUPREMA DE JUSTICIA

DE LA NACIÓN

haga lo que no puede, y además contempla implícitamente la posibilidad de que en esa institución no exista quien practique abortos, o no se lo haga allí, proponiendo la salida sin desentender al Estado de sus responsabilidades sanitarias.

\section{Colofón}

Lo que tiene que ver con la objeción de conciencia, sea individual o institucional, en suma, plantea dentro del mismo orden jurídico -entre la norma jurídica que tutela el derecho a conducirse de conformidad con la conciencia, y la norma jurídica que impone o veda una conducta determinada-, un conflicto difícil de resolver.

Pero de ninguna manera la solución, que está en manos y a cargo del Estado, puede violentar derechos reconocidos, obligando (bajo conminaciones sancionatorias) a realizar conductas reñidas con las más íntimos y profundas convicciones éticas de quien se pretende las ejecute. Su vigencia y ejercicio están igualmente protegidos por otras normas de igual jerarquía que los derechos que se pretenden garantizar aún compulsivamente- a quienes se considera titulares de otros derechos que están en pugna con los de aquéllos.

- Es el Estado, a través de sus instituciones de salud, quien debe garantizar los medios y los recursos para que los derechos de unos y de otros estén contemplados.

- Frente a un caso concreto, los profesionales del arte de curar, del ámbito público o privado, gozan siempre del derecho de objeción de conciencia, sin que su opción pueda implicar ninguna afectación adversa en lo personal, como en lo profesional o en lo laboral.

- Las instituciones públicas en que se desempeñan deben propender siempre a que se respeten los derechos de la mujer cuando solicita la interrupción de un embarazo en curso, invocando una situación eximente de responsabilidad penal (de las comprendidas en el Código Penal). Pero en todo caso, los y las profesionales tratantes, sin incurrir en violencia institucional de la mujer, no 
LA OBJECIÓN DE CONCIENCIA MÉDICA E INSTITUCIONAL

EN CASOS DE ABORTOS NO PUNIBLES. DERIVACIONES

DEL FALLO "F.,A.L." DE LA CORTE SUPREMA DE JUSTICIA

DE LA NACIÓN

están exentos de evaluar médica y legalmente, si concurren las condiciones para que dicha práctica sea viable y realizable en la institución.

- Las entidades de salud del ámbito privado, pueden ejercer el derecho a la objeción de conciencia institucional, y rehusarse a que en ellas se practiquen abortos.

- En caso que la institución no cuente con los medios y recursos necesarios, como tampoco con profesionales o auxiliares que no sean objetores de conciencia, o que (perteneciendo a la órbita privada) la institución no atienda tales casos, sus autoridades deben proveer a la derivación inmediata de la mujer encinta a otro centro asistencial, evitando siempre incurrir en demoras que conspiren contra la posibilidad de su realización, y que ponga en riesgo la salud o la vida de la paciente.

\section{Fuentes bibliográficas, normativas, jurisprudenciales y repositorios}

SARTEA, Claudio, en "¿Qué objeción? ¿qué conciencia? reflexiones acerca de la objeción de conciencia y su fundamentación conceptual", donde hace un comentario de "Rebelión en la granja" de George Orwell; en http://aebioetica.org/revistas/2013/24/82/391.pdf

Corte Suprema de Justicia de la Nación, Fallo completo en "F., A.L.", con los voto de los ministros Lorenzetti, Highton de Nolasco, Fayt, Maqueda y Zaffaroni; los ministros Petrachi y Argibay, votaron individualmente, de manera coincidente; en http://www.saij.gob.ar/corte-suprema-justicia-nacion-federal-ciudad-autonomabuenos-aires--medida-autosatisfactiva-fa12000021-2012-03-13/123456789-120o002-10ts-eupmocsollaf;

Ley 25.673, sancionada el 30/10/2002; promulgada el 21/11/2002; publicada en Boletín Oficial 22/11/2002; en

http://www.msal.gob.ar/images/stories/ryc/graficos/o000000677cnt-Leyes-quereconocen-tus-derechos.pdf;

Decreto $\mathrm{n}^{\circ}$ 1282/03 Fecha de Emisión: 23/05/2003; Publicado en: Boletín Oficial 26/05/2003. Ver texto completo en

https://www.argentina.gob.ar/normativa/nacional/decreto-1282-2003-

85450/texto; 
LA OBJECIÓN DE CONCIENCIA MÉDICA E INSTITUCIONAL EN CASOS DE ABORTOS NO PUNIBLES. DERIVACIONES

DEL FALLO "F.,A.L." DE LA CORTE SUPREMA DE JUSTICIA DE LA NACIÓN

“Guía Técnica para la Atención Integral de Abortos No Punibles"; texto completo en

http://www.msal.gob.ar/images/stories/bes/graficos/o000000667cnt-Guiatecnica-web.pdf

"Protocolo para la atención integral de las personas con derecho a la interrupción legal del embarazo"; texto completo en https://www.argentina.gob.ar/sites/default/files/protocolo ile.pdf

"Protocolo para la atención integral de las personas con derecho a la interrupción legal del embarazo"; texto actualizado al 10 de diciembre de 2019), en http://www.msal.gob.ar/images/stories/bes/graficos/o000001792cntprotocolo-ILE-2019-2edicion.pdf

Fuente: $\quad$ https://www.telam.com.ar/notas/201912/416154-provincias-queadhieren-al-protocolo-para-la-interrupcion-legal-del-embazo.html

Guía de Procedimiento para la Atención de Pacientes que soliciten Prácticas de Aborto no Punibles; Resolución $n^{\circ}$ 093/12, del Ministerio de Salud de la Provincia de Córdoba; texto completo en https://prensa.cba.gov.ar/salud-2/aborto-no-punible-guia-de-procedimiento/

Tribunal Superior de Justicia de la Provincia en "Portal de Belén" en https://www.justiciacordoba.gob.ar/JusticiaCordoba/Inicio/indexDetalle.aspx?co $\underline{\text { dNovedad }=11889}$

PADILLA, Norberto, en Anuario del Centro de Derecho Constitucional No 4, 2016 de la Universidad Católica Argentina, en

https://repositorio.uca.edu.ar/bitstream/123456789/2583/1/objecion-concienciaaborto-padilla.pdf

https://es.wikipedia.org/wiki/Abby Johnson

https://es.wikipedia.org/wiki/Patricia_Sandoval

https://www.lanacion.com.ar/opinion/el-grito-silencioso-del-aborto-nid1687935/

https://es.wikipedia.org/wiki/Anthony Levatino

https://www.actuall.com/vida/el-nuevo-doctor-nathanson-john-bruchalski-depracticar-abortos-a-dirigir-la-mayor-clinica-provida-en-virginia/

Ley 25.529; en

Ley 17.132; en

Academia Nacional de Medicina, Declaración del 28 de setiembre de 2000, en https://anm.edu.ar/wp-content/uploads/2018/o7/Objeci\%C3\%B3n-deconciencia.pdf

Academia Nacional de Medicina, Declaración en https://anm.edu.ar/wp- 
LA OBJECIÓN DE CONCIENCIA MÉDICA E INSTITUCIONAL EN CASOS DE ABORTOS NO PUNIBLES. DERIVACIONES

DEL FALLO "F.,A.L." DE LA CORTE SUPREMA DE JUSTICIA DE LA NACIÓN

content/uploads/2018/07/Consideraciones-sobre-el-aborto.pdf

Academia Nacional de Medicina, Declaración en www.acamedbai.org.ar

Academia Nacional de Medicina, Declaración en https://anm.edu.ar/wpcontent/uploads/2018/07/ABORTOYOBJECIONDECONCIENCIA.pdf

Academia Nacional de Medicina, Declaración en https://anm.edu.ar/wpcontent/uploads/2018/07/1.pdf;

Nota del 25 de junio de 2018 presentada a los Senadores nacionales, en https://www.impulsobaires.com.ar/amp/265578/abogados_a_los_senadores_la_ ley_de_aborto_es_groseramente_inconstitucional/

Decreto reglamentario ${ }^{\circ}$ 1282/2003, Fecha de Emisión: 23/05/2003; Publicado en: Boletín Oficial 26/05/2003. Ver texto completo en https://www.argentina.gob.ar/normativa/nacional/decreto-1282-2003$\underline{85450 / \text { texto }}$

ASIAIN PEREIRA, Carmen, Objeción de Conciencia. Tribunal de máximo rango anula con efectos generales y absolutos decreto que la restringía, en Revista de Derecho Público, noviembre de 2015, $\mathrm{N}^{\mathrm{O}} 48$, en www.revistaderechopublico.com/revistas/48/ asiain.php\#reft46; citada por Norberto Padilla en el artículo mencionado anteriormente. 